\title{
Evolutionary Game Research on the Impact of Environmental Regulation on Overcapacity in Coal Industry
}

\author{
Bo Fan, ${ }^{1,2}$ Tingting Guo $\mathbb{D}^{2},{ }^{2}$ Ruzhi Xu $\mathbb{D}^{2},{ }^{2}$ and Wenquan Dong ${ }^{3}$ \\ ${ }^{1}$ School of Earth Sciences and Resources, China University of Geosciences (Beijing), Beijing 100191, China \\ ${ }^{2}$ School of Finance, Qilu University of Technology, Jinan, Shandong 250100, China \\ ${ }^{3}$ Department of Industrial and Systems Engineering, The University of Tennessee, Knoxville, TN 37996, USA
}

Correspondence should be addressed to Ruzhi Xu; xrz@qlu.edu.cn

Received 2 February 2021; Revised 26 February 2021; Accepted 5 March 2021; Published 17 March 2021

Academic Editor: Ming Bao Cheng

Copyright ( $(2021$ Bo Fan et al. This is an open access article distributed under the Creative Commons Attribution License, which permits unrestricted use, distribution, and reproduction in any medium, provided the original work is properly cited.

\begin{abstract}
Currently, the world is facing two significant challenges: low-carbon development and overcapacity. Government departments must reexamine their development strategy of energy industry. Implementing environmental regulatory policies and technological innovation can help alleviate coal industry's overcapacity, while sustainable development requires joint actions of governments, enterprises, and the market. Based on the evolutionary game theory, this study constructs a tripartite evolutionary game model of local government, power industry, and coal enterprise. Under the premise of bounded rationality, the evolution path of each player in the game under the market incentive environmental regulation is analyzed, and the influence of the change of parameters of each player on the result is numerically simulated. The study found that strengthening environmental regulation by local governments is an inevitable choice to promote the transformation and upgrading of coal industry and power industry. In addition, reducing law enforcement costs and technological innovation costs are the fundamental point of the coordinated development of the three parties. Technological innovation in the power industry will reduce the probability of coal companies' choosing clean production strategies, while seeking low-cost clean production technology and financial support is the key to coal companies' optimization of production capacity.
\end{abstract}

\section{Introduction}

Environmental protection has always been the focus of all countries' attention, and many countries are pursuing more stringent environmental regulations to achieve green and low-carbon development. The Kyoto Protocol and the Paris Agreement signed by many countries aim to control greenhouse gas emissions; however, economic growth is inevitably accompanied by substantial increase in power generation [1]. Due to its low prices and large reserves, coal is widely used in energy-intensive industries such as power generation and heating. However, a large amount of carbon dioxide is emitted during coal mining and use. About $40 \%$ of global greenhouse gas emissions come from coal consumption [2]. Many countries and regions have called for a suspension of coal mining [3] and sought new ways of clean production, such as increasing the proportion of renewable energy and clean energy in power generation $[4,5]$. However, with relatively high cost of promoting and utilizing renewable energy and the low feasibility in the short term [6], the emission reduction targets for complete decarbonization of the power sectors in many countries remain unachievable. On the other hand, although countries like China, the United States, and other major energy consumers have restricted coal mining to meet their increasing demand for electricity, coal-fired power remains dominant in most developing countries $[7,8]$. Notably, as an essential resource for the industrial economic development, the scale of coal trading is still enormous; meanwhile, the scale of the coal industry's backward production capacity is gradually expanding as well. Since coal overcapacity causes a waste of investment and destroys the ecological environment and seriously endangers human society's sustainable development [9], how to use coal resources reasonably while 
protecting the environment is a significant problem that needs to be solved urgently.

Overcapacity is a common problem [10]. Take China, which ranks first in energy consumption, as an example. The 2016 Central Economic Work Conference listed "de-capacity" as the first of the five major structural reform tasks, and various coal de-capacity policies have been introduced since then. However, in 2019, China's coal overcapacity scale has reached 210GW-260GW [11], which meant that the coal overcapacity remained relatively serious. The Chinese government must strengthen its environmental regulations and supervision of high-polluting industries such as coal and electricity before reaching the "threshold" that the ecological environment can withstand [12] so that to realize its promise of extremely challenging emission reduction to peak carbon dioxide emissions in 2030. Although environmental regulations are conducive to improving the utilization rate of energy companies and adjusting overcapacity [13], existing environmental regulations may become rigid under different socioeconomic conditions [14], let alone that it takes a long time before the backward production capacity is eliminated from market. Therefore, specific implementation of environmental regulations by local governments is the key to optimizing the production capacity structure and improving the ecological environment. The rules and regulations promulgated by the government can help speeding up the elimination of "zombie companies" in the coal industry and accelerate the pace of de-capacity [15]. Since coal industry and power industry belong to an industrial symbiosis system, under the influence of environmental regulations and other policies, the power sector is in a critical period of transformation and upgrading, which will lead to a sharp decline of the demand for coal in the future [16]. If the coal industry does not carry out green innovation in time, it will inevitably run adrift of the market needs. On the other hand, many studies have proved that for countries such as China, India, and Russia, where coal occupies a fundamental position in energy, as well as regions where coal occupies a significant proportion of the energy mix (such as the European Union), the key to energy transition is to promote clean and efficient coal use [17-19]. In summary, resolving coal overcapacity is a process of dynamic equilibrium that requires the cooperation of government, coal companies, and power industry, which will help optimize the industrial structure while ensuring the quality of capacity reduction and better achieving green and low-carbon development.

When studying the evolution of overcapacity under environmental regulations, time, changes in supervision efforts, and the learning capabilities of interest bodies need to be taken into consideration [20]. Therefore, given the assumptions of bounded rationality and decision-making dynamics in the evolutionary game theory, many scholars have explored the impact of environmental regulations on enterprise innovation and overcapacity by constructing evolutionary game models. As the primary consumers of coal companies, power industry is closely related to coal industry and both are affected by environmental regulations.
Furthermore, the coal purchase plan and power generation technology innovation in the power industry also affect coal companies' production capacity. However, the existing related researches, which mainly focus on the game between the central government, local governments, and coal enterprises [21-23], lack the investigation of external factors such as the market supply and demand environment [24]. In this respect, this paper uses evolutionary game theory to contemplate the intensity of carbon emission reduction and coal market demand after technological upgrading in the coal and power industries, and studies the behavioral strategy relationship and dynamic evolution mechanism among the three-party game players of the local government, power industry, and coal enterprises under different constraint scenarios so as to provide a theoretical reference for the government to regulate and control related policy systems and help coal companies to break through the dilemma of overcapacity with the goal of low-carbon development.

Compared with existing researches, this study mainly makes contributions on the following aspects:

(1) This study not only contemplates the game between regulatory agencies and enterprises but also takes the primary consumers of coal, namely, the power industry, as one of the main players in the game and constructs a three-party evolutionary game model (different from $[20,21]$ ) to analyze how the tripartite game's leading players coordinate to promote the transformation and upgrading of high-polluting coal industries and power industries under the premise of bounded rationality.

(2) Existing researches do not incorporate environmental taxes and market factors into the game model. This paper takes the market-incentive environmental regulations adopted by China, a major coal consumer, as an example. Through numerical simulation of initial strategy selection, environmental taxes, and government subsidies and penalties, as well as costs and performance of innovation, we analyze the influence of different environmental regulations and other factors on the evolution path of coal enterprises and the power industry.

(3) According to the results of the evolutionary game analysis, the key factors affecting the stability of the evolutionary game are found. It is concluded that local governments may strengthen environmental regulations and solve overcapacity by promoting technological innovation of enterprises (different from [25-27]), specifically, by increasing environmental taxes and increasing subsidies and penalties simultaneously, and the effect of strengthening penalties is particularly significant. When the amount of coal saved by technological innovation reaches a certain threshold, the power industry will actively carry out technological innovation. Although the power industry is a close strategic partner of coal companies, the power industry's 
technological innovation strategies will have a negative incentive for coal companies' cleaner production. Therefore, reducing the cost of technological innovation is the key to promoting the coordinated development of coal and power industries.

The rest of this paper is organized as follows: Section 2 reviews relevant literature; Section 3 constructs a tripartite evolutionary game model of local government, power industry, and coal enterprises; Section 4 analyzes the evolutionary stability of individual game player and the game system; Section 5 carries out numerical simulations to verify and analyze the research conclusions; Section 6 summarizes the research results of this study and puts forward corresponding policy recommendations.

\section{Literature Review}

This paper aims to study the impact of environmental regulations on the overcapacity of the coal industry and conduct a quantitative analysis through evolutionary game theory. The literature related to this study mainly relates to the impact of environmental regulations on enterprise innovation and overcapacity, the causes and solutions of overcapacity, which are reviewed on the following aspects.

The first aspect considers the impact of environmental regulations on corporate innovation and overcapacity. Innovation involves complex interaction between an enterprise and its environment. Shao et al. [28] believed that the impact of environmental regulatory policies on enterprise innovation can be roughly divided into four aspects: technological innovation, product innovation, institutional innovation, and ecological innovation. According to the "Porter Hypothesis," reasonable environmental regulations will stimulate enterprises to carry out technological innovation and achieve a win-win situation of improving enterprise competitiveness and reducing emissions [29]. Without mandatory requirement of environmental policy, due to the externality of innovation, the marginal cost of technological innovation of enterprises in the short term is much higher than the marginal benefit, which would impede enterprises from carrying out technological innovation due to lack of sufficient motivation [30]. Based on the "Porter Hypothesis," scholars have concluded that there is a U-shaped relationship between the intensity of environmental regulation and overcapacity, and a significant inverted U-shaped relationship with enterprise technological innovation [31], that is, before reaching a certain threshold, higher environmental regulations will improve the technological innovation capabilities of enterprises and alleviate overcapacity. For example, improving environmental regulation can increase the utilization rate of industrial capacity [32], accelerate the exit of "zombie companies" in the coal industry, and promote the governance of energy companies' capacity issues [15]. By an empirical analysis of 12 resource-based industries in China, $\mathrm{Li}$ et al. [33] pointed out that environmental regulations have a significant role in promoting technological innovation in the lagging period of resource-based industries. Ren et al.
[34] divided China's environmental regulations into three types: command-controlled, market-incentive, and voluntary-consciousness. Command-controlled regulations refer to the government's enactment of environmental laws and policies to enforce emission reduction; market-incentive regulations refer to the use of economic means such as the collection of sewage charges, emission taxes, etc., to limit corporate pollution emissions; voluntary-consciousness regulations refer to citizens actively supervising corporate emissions and protecting the environment. And different types of environmental regulations have different impacts on enterprise innovation. Chen et al. [35] pointed out that mandatory emission reduction is the main reason for the overcapacity in the southeast coastal area of China. Pan et al. [36] found that technological innovation can improve energy efficiency. In the long run, compared with commandcontrolled environmental regulations, market-incentive environmental regulations have more incentives and longterm effects on technological innovation and significantly improve energy efficiency. In addition, carbon tax has a positive effect on energy saving and emission reduction and can restrain energy consumption [37].

We can see that most of the literature focuses on the comparison of the policy effects of different types of environmental regulations, and this paper studies the impact of specific types of environmental regulations on the overcapacity of specific industries, which is mainly manifested through enterprise technological innovation.

The second aspect considers the causes and solutions of overcapacity. Generally speaking, the factors that cause overcapacity are related to both supply and demand: overheated investment on the supply side, uncertainty in demand, reduced exports, information asymmetry, etc. In addition, the government's regulatory failure will also promote overcapacity $[32,38]$. Coal overcapacity has many impacts on economic development and the environment, such as a sharp decline in coal prices, which may cause loss or even bankruptcy of a great number of companies [39], and unreasonable allocation of economic resources, which thereby hinders investment on renewable energy. Scholars have found that although China's current de-capacity policy has achieved some results to a certain degree, there are still drawbacks. Shi et al. [40] pointed out that China's blind coal reduction policy cannot solve the fundamental problem. It is necessary to consider regional heterogeneity, and it would be more reasonable to use market tools to regulate and control capacity. Following a SWOT analysis on the safety and environmental laws and regulations of China and the United States, Dzonzi-Undi and Li [41] pointed out that a series of policies related to coal production safety and environmental protection formulated by China have insignificant effects on promoting safe production, environmental protection investment, and technology research and development, and only reduced the number of deaths. Regarding specific measures to resolve overcapacity, Zhang et al. [42] pointed out that eliminating backward units and regulating power generation prices can help improve energy efficiency. The implementing of environmental regulation policies are conducted by the central government and local 
governments, where the central government is the target maker, and the local governments have actual control over the specific implementation of the target [43]. However, due to the pursuit of different interests, the effect of local governments in improving overcapacity policies is better than that of the central government [44], and the influence of local governments on carbon emission reduction is more significant than that of enterprises [45]. The government can use policy means to coordinate multi-interest bodies [46], which shows that local governments play an important role in capacity control and environmental protection.

The above literature on resolving overcapacity mostly focuses on the research of strategies between regulatory agencies. This paper focuses on the interaction between regulatory agencies and enterprises, as well as between enterprises and enterprises. We take the environmental regulation policies implemented in China as an example, assuming that local governments must implement the central government's relevant regulations on environmental regulation and mainly adopt market-incentive environmental regulations and adjust their regulatory intensity according to actual conditions.

To sum up, the key to resolving overcapacity lies in the close and reasonable arrangements of the government, enterprises, and consumers. Researches nowadays focus on the policy effects of government departments' implementation of environmental regulations on corporate overcapacity and do not place market factors in the same research framework. On the contrary, this study incorporates environmental taxes, government subsidies, and penalties, as well as innovation performance into the model. Through the three-party evolutionary game analysis of local government, power industry, and coal enterprises, we provide a reference for resolving the problem of coal overcapacity and the establishment of a market-oriented overcapacity early warning mechanism. The research differences between this study and other papers are shown in Table 1.

\section{Problem Analysis and Model Construction}

3.1. Problem Analysis and Model Assumptions. Overcapacity leads to a decline in coal prices, which increases global coal demand again. Faced with huge environmental pressure, if not strictly controlled, such a situation will fall into a vicious circle, according to which, as the executor of environmental regulations and policies, local governments must adjust the intensity of regulations. The implementation of environmental regulations has brought a considerable impact on coal-fired power plants, and the power industry is closely related to coal companies whose overcapacity is mostly affected by the amount of coal used in the power industry. Both players are susceptible to environmental protection policies. Based on the logical relationship diagram shown in Figure 1, this study explains the game between local governments, coal companies, and power industry players under market-incentive environmental regulations.
Figure 1 shows that the implementation of environmental regulations by local governments will impact the coal companies and power industries. The transformation and upgrading of thermal power plants to increase clean energy use will reduce the demand for coal and the operating income of coal companies. As coal enterprises are affected by environmental regulations, to make up for the loss of income and meet future sustainable development, the probability of choosing cleaner production will increase, and coal production capacity will be in a more reasonable range. Conversely, if power plants maintain the original coal demand, the probability of coal companies choosing cleaner production will also decrease, which will exacerbate coal overcapacity.

Based on the above analysis, before constructing an evolutionary game model among local governments, power industry, and coal companies, the following assumptions are made:

(1) There are 3 players in the evolutionary game model, assuming the local government as player 1 , the power industry as player 2 , and coal companies as player 3 , and all three are bounded rational decision-makers.

(2) The "Environmental Protection Tax Law of PRC" came into effect on January 1, 2018, levying environmental protection taxes on air pollutants, water pollutants, solid pollutants, and noise. The damage to the ecological environment by the power industry and coal companies is prominently manifested in air pollution and water pollution [54]. The tax rate of air pollutants is $1.2 \mathrm{RMB}$ to $12 \mathrm{RMB}$ per pollution equivalent while the tax rate of water pollutants is 1.4 $\mathrm{RMB}$ to $14 \mathrm{RMB}$ per pollution equivalent. Local governments can levy environmental taxes 1-10 times the minimum standard. Therefore, it is assumed that each region's environmental tax standard is 1.2-14 RMB per pollution equivalent, which is set as $B$. When local governments strengthen environmental regulations, the cost paid is $C_{1}$. Local governments mainly impose environmental taxes on coal-fired power companies by levying $B /$ per pollution equivalent standards, take financial or administrative penalties $P$ for polluting companies that do not innovate in technology or maintain current production capacity, and subsidize $S$ for companies that upgrade their technology to seek cleaner production, so as to force coal companies and the power industry to conduct clean production, alleviate the problem of overcapacity, and protect the local environment. According to the actual situation, it is assumed that $C_{1}<P-S$. Technological innovation by either the power industry or coal companies can bring additional environmental benefits $R$ to the local area. If both parties choose technological innovation, the local government's environmental benefits will be $2 R$. There is a principal-agent relationship between the central government and local governments. When energy governance intensifies conflict of interest, local governments will choose to 
TABLE 1: Papers that are most related to our research.

\begin{tabular}{|c|c|c|c|c|c|}
\hline Literature & Government department & Power industry & Coal industry & Environmental regulation & Technological innovation \\
\hline [29] & & & & $\sqrt{ }$ & $\sqrt{ }$ \\
\hline$[47]$ & & & & $\sqrt{ }$ & $\sqrt{ }$ \\
\hline$[48]$ & & $\sqrt{ }$ & $\sqrt{ }$ & $\sqrt{ }$ & \\
\hline [49] & & $\sqrt{ }$ & $\sqrt{ }$ & $\sqrt{ }$ & $\sqrt{ }$ \\
\hline$[50]$ & $\sqrt{ }$ & $\sqrt{ }$ & $\sqrt{ }$ & & $\sqrt{ }$ \\
\hline [51] & $\sqrt{ }$ & & & $\sqrt{ }$ & $\sqrt{ }$ \\
\hline$[22]$ & $\sqrt{ }$ & & & $\sqrt{ }$ & \\
\hline$[52]$ & $\sqrt{ }$ & $\sqrt{ }$ & & $\sqrt{ }$ & $\sqrt{ }$ \\
\hline$[53]$ & & & $\sqrt{ }$ & $\sqrt{ }$ & $\sqrt{ }$ \\
\hline This paper & $\sqrt{ }$ & $\sqrt{ }$ & $\sqrt{ }$ & $\sqrt{ }$ & $\sqrt{ }$ \\
\hline
\end{tabular}

Source: authors' compilation.

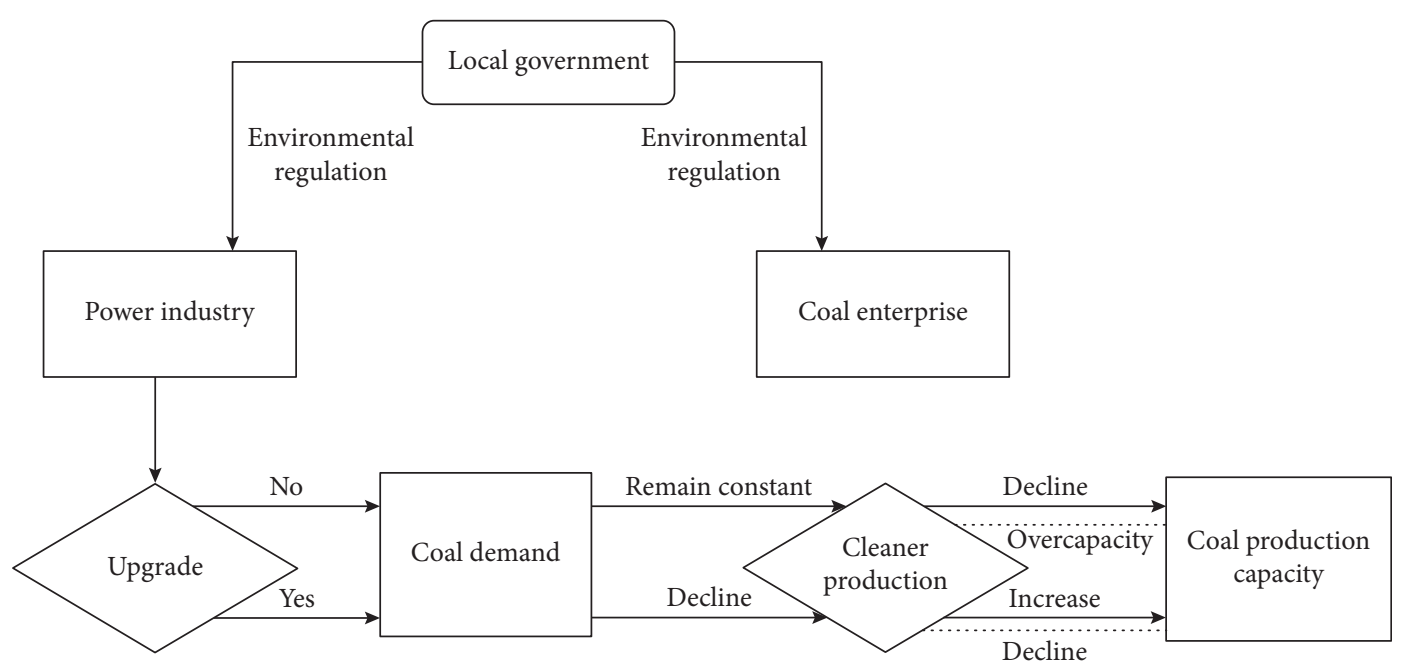

FIgURE 1: Logical relationship diagram of the three-party evolutionary game.

continue relatively loose environmental regulatory arrangements to seek a balance between environmental regulations and the economic benefits of local industries. It is assumed here that local governments only impose environmental taxes on power industry and coal companies. When the local environmental pollution is severe, or coal overcapacity protrudes, the local government will be held accountable by the higher-level competent authority, and the corresponding administrative penalty $F$, and $F>C_{1}$. In summary, the strategy set of local governments is (strengthening regulations, maintaining current regulations), $B \in[1.2,14]$.

(3) Nowadays, the proportion of coal power remains high in China's power industry, accounting for about $70 \%$. Hydropower development has slowed down while clean energy power generation such as wind power and photovoltaics has developed rapidly; however, the proportion of its total installed capacity is still small [55] and coal-fired thermal power units still rely mainly on load reduction. Besides, starting from January 1, 2020, China has abolished the coalelectricity linkage mechanism, allowing the market to set part of coal-fired power generation prices, which affects the profits of the power industry. With the improvement of environmental regulations, the amount of coal used in the power industry decreases, and the demand for clean energy is gradually increasing. The power industry chooses technological innovation to transform, upgrade, and adjust the structure of energy use. In this respect, the amount of coal saved is $Q$, the cost paid for technological innovation is $C_{2}$, the increase in income after technological innovation is $I_{2}$, and the initial emissions of power industry are $G_{2}$. If the power industry carries out technological innovations, the emission reductions $t_{2} G_{2}$ can be brought about, and the environmental taxes and fees that can be saved are $B t_{2} G_{2}$. However, if the cost of technological innovation is too high, the cost of environmental compliance is accordingly too low, or the cost gap between the use of coal and new energy is too small, then the power industry is likely to maintain the current coal consumption. Therefore, the power industry strategy set is (technical innovation, remaining unchanged), $t_{2} \in(0,1)$. 
(4) Affected by environmental regulations, low-carbon environmental protection requirements have become increasingly stringent. The cost of environmental compliance for coal companies has increased so much that if coal companies maintain their existing capacity, hedging risks will be challenging. Considering that the transformation and upgrading of the power industry will exacerbate the overcapacity issue, coal enterprises seek ways to clean and efficient use of coal with a cost of $C_{3}$ and the increase in revenue from cleaner production of $I_{3}$. Assuming that the current emissions of coal enterprises are $G_{3}$, and the emission reduction that cleaner production can bring is $t_{3} G_{3}$, the environmental tax savings would be $B t_{3} G_{3}$. However, when coal companies' cost of pollutant discharge is lower than the cost of cleaner production, or the power industry maintains the current demand for coal, companies will choose to maintain unchanged. As China's coal industry is in a buyer's market, if the coal company fails to adjust the production capacity after the technological innovation of the power company, it will cause overcapacity, and the price in this case is $U_{0}$; if the coal enterprise conducts clean production, the coal price is $U_{1}, U_{0}<U_{1}$. Therefore, the possible strategic combination of coal companies is cleaner production, remaining unchanged.

Assuming that under bounded rationality, the probabilities that local governments choose to strengthen environmental regulation and maintain the current intensity are $x$ and $1-x$, respectively; the probabilities that the power industry chooses technological innovation and remains unchanged are $y$ and $1-y$, respectively; the probabilities that coal companies choose cleaner production and remain unchanged are $z$ and $1-z$, respectively, $x, y, z \in[0,1]$.

3.2. Payoff Matrix of the Tripartite Evolutionary Game. According to the above assumptions, the payoff matrix of the three parties, namely, local government, power industry, and coal enterprise is so obtained (Table 2).

\section{Evolutionary Game Model Solving and Stability Analysis}

4.1. Stability Analysis of Local Government. Assuming that the expected profit when the local government chooses the strategy of "strengthening regulation" is $U_{x}$, the expected profit when the local government chooses the strategy of "maintaining the current regulation" is $U_{1-x}$, and the average expected profit is $\overline{U_{1}}$, we can obtain

$$
\left\{\begin{array}{l}
U_{x}=y z\left[2 R-B\left(t_{2} G_{2}+t_{3} G_{3}\right)-2 S-C_{1}\right]+y(1-z)\left[R-B t_{2} G_{2}-S+P-C_{1}\right] \\
+(1-y) z\left[R-B t_{3} G_{3}+P-S-C_{1}\right]+(1-y)(1-z)\left[2 P-C_{1}\right] \\
U_{1-x}=y z\left[2 R-B\left(t_{2} G_{2}+t_{3} G_{3}\right)\right]+y(1-z)\left[R-B t_{2} G_{2}\right] \\
+(1-y) z\left[R-B t_{3} G_{3}\right]+(1-y)(1-z)(-F) \\
\overline{U_{1}}=x U_{x}+(1-x) U_{1-x}
\end{array}\right.
$$

The replication dynamic equation of the local government strategy selection is

$$
\begin{aligned}
F(x)= & \frac{\mathrm{d} x}{\mathrm{~d} t}=(1-x) x\left[-C_{1}+2 P+F(y-1)(z-1)\right. \\
& -(P+S)(y+z)] .
\end{aligned}
$$

Taking the derivative of $F(x)$,

$$
\begin{aligned}
\frac{\mathrm{d} F(x)}{\mathrm{d} x}= & (1-2 x)\left[-C_{1}+2 P+F(y-1)(z-1)\right. \\
& -(P+S)(y+z)] .
\end{aligned}
$$

Let $F(x)=0$, we can get $x=0, x=1, y=-\left(\left[C_{1}-F-\right.\right.$ $2 P+(F+P+S) z]) /(F+P+S-F z)=y^{*}$, according to the stability theorem of differential equations, if the probability that the local government chooses to strengthen environmental regulation is in a stable state, it must meet the conditions that $F(x)=0$ and $\mathrm{d}(F(x)) / \mathrm{dx}<0$. When $y=y^{*}$, we can get $F(x) \equiv 0$, any value of $x$ is an evolutionary stable strategy of the local government, and the local government strategy does not change with time. When $y \neq y^{*}$, there will be two situations that result:

(1) When $C_{1}-F-2 P+(F+P+S) z<0$, we can get $y^{*}>0$. For any $y$ in the interval $[0,1]$, when $y>y^{*}$, we can get $\mathrm{d} F(x) /\left.\mathrm{d} x\right|_{x=1}>0$ and $\mathrm{d} F(x) /\left.\mathrm{d} x\right|_{x=0}<0$. Thus, $\mathrm{x}=0$ is the steady state. When $y<y^{*}$, we can get $\mathrm{d} F(x) /\left.\mathrm{d} x\right|_{x=1}<0$ and $\mathrm{d} F(x) /\left.\mathrm{d} x\right|_{x=0}>0$. Thus, $x=1$ is the steady state.

(2) When $C_{1}-F-2 P+(F+P+S) z>0$, we can get $y^{*}<0$. Because $y \in[0,1]$, then $y>y^{*}$ is held, we can get $\mathrm{d} F(x) /\left.\mathrm{d} x\right|_{x=1}>0$ and $\mathrm{d} F(x) /\left.\mathrm{d} x\right|_{x=0}<0$. Thus, $x=0$ is the steady state. Figure 2 shows the evolution of local government strategies.

Proposition 1. The probability that the local government chooses the strategy of "strengthening environmental regulation" is positively related to the penalty amount imposed by the superior authority on the local government, the punishment income from strengthening environmental regulation, and the cost of strengthening environmental regulation, and is 
TABle 2: Payoff matrix.

\begin{tabular}{llc}
\hline Local government $\quad$ Power industry & Coal enterprises \\
Remain unchanged $(1-z)$
\end{tabular}

$$
\text { Technical innovation }(y) \quad\left[\begin{array}{c}
2 R-B\left(t_{2} G_{2}+t_{3} G_{3}\right)-2 S-C_{1} \\
I_{2}+S+Q U_{1}+B t_{2} G_{2}-C_{2} \\
I_{3}+S-Q U_{1}+B t_{3} G_{3}-C_{3}
\end{array}\right] \quad\left[\begin{array}{c}
R-B t_{2} G_{2}-S+P-C_{1} \\
I_{2}+S+Q U_{0}+B t_{2} G_{2}-C_{2} \\
-Q U_{0}-P
\end{array}\right]
$$

Strengthen regulations $(x)$

$$
\text { Remain unchanged }(1-y) \quad\left[\begin{array}{c}
R-B t_{3} G_{3}+P-S-C_{1} \\
-P \\
I_{3}+S+B t_{3} G_{3}-C_{3}
\end{array}\right] \quad\left[\begin{array}{c}
2 P-C_{1} \\
-P \\
-P
\end{array}\right]
$$

Maintain current regulations $(1-x)$

$$
\left[\begin{array}{c}
2 R-B\left(t_{2} G_{2}+t_{3} G_{3}\right) \\
I_{2}+Q U_{1}+B t_{2} G_{2}-C_{2} \\
I_{3}-Q U_{1}+B t_{3} G_{3}-C_{3}
\end{array}\right] \quad\left[\begin{array}{c}
R-B t_{2} G_{2} \\
I_{2}+Q U_{0}+B t_{2} G_{2}-C_{2} \\
-Q U_{0}
\end{array}\right]
$$

$$
\text { Remain unchanged }(1-y) \quad\left[\begin{array}{c}
R-B t_{3} G_{3} \\
0 \\
I_{3}+B t_{3} G_{3}-C_{3}
\end{array}\right] \quad\left[\begin{array}{c}
-F \\
0 \\
0
\end{array}\right]
$$
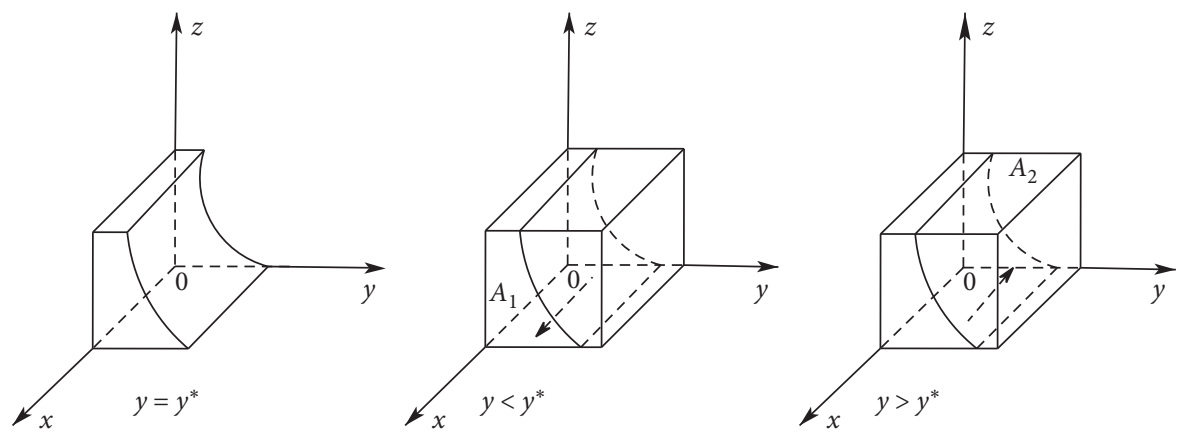

Figure 2: Phase diagram of strategy evolution of the local government.

negatively related to the cost of strengthening environmental regulations and the number of subsidies to enterprises.

Proof. Figure 2 shows that the probability of local governments adopting the strategies of "strengthening environmental regulations" and "maintaining current regulation" is the volume of space $A_{1}$ and $A_{2}$, respectively, calculated as

$$
\begin{aligned}
V_{A_{1}} & =\int_{0}^{1} \int_{0}^{1}-\left[C_{1}-F-2 P+(F+P+S) z\right] \mathrm{d} x \mathrm{~d} z \\
& =\frac{\left[-2 C_{1}+F+3 P-S-(F+2(P+S)) y\right]}{2} \\
V_{A_{2}} & =1-V_{A_{1}} .
\end{aligned}
$$

According to the expression of $V_{A_{1}}$ when the local government adopts the strategy of "strengthening environmental regulation," the first-order partial derivative of each element can be obtained: $\mathrm{d} V_{A_{1}} / \mathrm{d} F>0, \mathrm{~d} V_{A_{1}} / \mathrm{d} P>0$, $\mathrm{d} V_{A_{1}} / \mathrm{d} C_{1}<0, \mathrm{~d} V_{A_{1}} / \mathrm{d} S<0$. In summary, the increase in penalties imposed by higher-level authorities on local governments, the increase in revenue from fines coming with strengthening environmental regulations, or the reduction in the cost of strengthening environmental regulations and the reduction of subsidies can all increase the probability of local governments' strengthening of environmental regulations.

Proposition 2. The probability that the local government chooses the strategy of "strengthening environmental regulation" is negatively related to the probability that the power industry chooses "technical innovation" and the probability that coal companies choose "cleaner production."

Proof. When $z<-\left(\left[C_{1}-F-2 P+(F+P+S) y\right]\right) /(F+P+$ $S-F y)$ and $y<y^{*}$, we can get $\mathrm{d} F(x) /\left.\mathrm{d} x\right|_{x=1}<0$, thus, $x=1$ is the steady state; otherwise, $x=0$ is the steady state. Therefore, with the gradual increase in $y$ and $z$, the evolutionary stabilization strategy of local governments will be 
reduced from $x=1$ (strengthening environmental regulations) to $x=0$ (maintaining current regulations).

The probability that the local government chooses the strategy of "strengthening environmental regulation" will decrease with the increase of the probability that the power industry chooses the strategy of "technological innovation" and the probability that coal companies choose "cleaner production." It shows that the active technological innovation of pollutant companies may slow down the process of local governments' strengthening of environmental regulations.

4.2. Stability Analysis of the Power Industry. Assuming that the expected profit when the power industry chooses the "technical innovation" strategy is $U_{y}$, the expected profit when the power industry chooses the "remain unchanged" strategy is $U_{1-y}$, and the average expected profit is $\overline{U_{2}}$, we can obtain

$$
\left\{\begin{array}{l}
U y=x z\left(I_{2}+S+Q U_{1}+B t_{2} G_{2}-C_{2}\right)+x(1-z)\left(I_{2}+S+Q U_{0}+B t_{2} G_{2}-C_{2}\right) \\
+(1-x) z\left(I_{2}+Q U_{1}+B t_{2} G_{2}-C_{2}\right)+(1-x)(1-z)\left(I_{2}+Q U_{0}+B t_{2} G_{2}-C_{2}\right), \\
U_{1-y}=x z(-P)+x(1-z)(-P), \\
\overline{U_{2}}=y U_{y}+(1-y) U_{1-y} .
\end{array}\right.
$$

The replication dynamic equation of the power industry strategy selection is

$$
\begin{aligned}
F(y)= & \frac{\mathrm{d} y}{\mathrm{~d} t}=(1-y) y\left[-C_{2}+I_{2}+B G_{2} t_{2}+(P+S) x\right. \\
& \left.+Q\left(U_{0}(1-z)+U_{1} z\right)\right] .
\end{aligned}
$$

Taking the derivative of $F(y)$,

$$
\begin{aligned}
\frac{\mathrm{d} F(y)}{\mathrm{d} y}= & (1-2 y)\left[-C_{2}+I_{2}+B G_{2} t_{2}+(P+S) x\right. \\
& \left.+Q\left(U_{0}(1-z)+U_{1} z\right)\right] .
\end{aligned}
$$

Let $F(y)=0$, we can get $y=0, y=1, z=\left[-C_{2}+I_{2}+\right.$ $\left.B G_{2} t_{2}+Q U_{0}+(P+S) x\right] / Q\left(U_{0}-U_{1}\right)=z^{*}$, according to the stability theorem of differential equations, if the probability of choosing technological innovation in the power industry is stable, it must meet the conditions that $F(y)=0$ and $\mathrm{d}(F(y)) / \mathrm{d} y<0$. When $z=z^{*}$, we can get $F(y) \equiv 0$, any value of $y$ is an evolutionary stable strategy of the power industry, and the strategy of the power industry does not change over time. When $z \neq z^{*}$, there are two situations that result:

(1) When $-C_{2}+I_{2}+B G_{2} t_{2}+Q U_{0}+(P+S) x<0$, we can get $z^{*}>0$. For any $z$ in the interval $[0,1]$, when $z>z^{*}$, we can get $\mathrm{d} F(y) /\left.\mathrm{d} y\right|_{y=1}<0$ and $\mathrm{d} F(y) /\left.\mathrm{d} y\right|_{y=0}>0$. Thus, $y=1$ is the steady state. When $z<z^{*}$, we can get $\mathrm{d} F(y) /\left.\mathrm{d} y\right|_{y=1}>0$ and $\mathrm{d} F(y) /\left.\mathrm{d} y\right|_{y=0}<0$. Thus, $y=0$ is the steady state.

(2) When $-C_{2}+I_{2}+B G_{2} t_{2}+Q U_{0}+(P+S) x>0$, we can get $z^{*}<0$. Because $z \in[0,1]$, then $z>z^{*}$ is held, we can get $\mathrm{d} F(y) /\left.\mathrm{d} y\right|_{y=1}<0$ and $\mathrm{d} F(y) /\left.\mathrm{d} y\right|_{y=0}>0$. Thus, $y=1$ is the steady state. The strategy evolution diagram of power industry is shown in Figure 3.

Proposition 3. The probability that the power industry chooses the "technological innovation" strategy is positively related to the increase in revenue brought by technological innovation in the power industry, government subsidies and penalties, the environmental taxes that can be saved, and the increase in the cost of saving coal, and is negatively related to technology research and development costs.

Proof. Figure 3 shows that the probability that the power industry adopts "remaining unchanged" and "technological innovation" strategies are the volumes of $B_{1}$ and $B_{2}$, respectively, calculated as

$$
\begin{aligned}
V_{B_{1}} & =\int_{0}^{1} \int_{0}^{1} \frac{\left[-C_{2}+I_{2}+B G_{2} t_{2}+Q U_{0}+(P+S) x\right]}{Q\left(U_{0}-U_{1}\right)} \mathrm{d} x \mathrm{~d} y \\
& =\frac{\left[-2 C_{2}+2 I_{2}+P+S+2 B G_{2} t_{2}+2 Q U_{0}\right]}{2 Q\left(U_{0}-U_{1}\right)}, \\
V_{B_{2}} & =1-V_{B_{1}}=\frac{\left[-2 C_{2}+2 I_{2}+P+S+2 B G_{2} t_{2}+2 Q U_{1}\right]}{2 Q\left(U_{1}-U_{0}\right)} .
\end{aligned}
$$

According to the expression of $V_{B_{2}}$, when the power industry adopts the strategy of "technical innovation," the first-order partial derivative of each element can be obtained: $\mathrm{d} V_{B_{2}} / \mathrm{d} C_{2}<0, \quad \mathrm{~d} V_{B_{2}} / \mathrm{d} I_{2}>0, \quad \mathrm{~d} V_{B_{2}} / \mathrm{d} P>0, \quad \mathrm{~d} V_{B_{2}} / \mathrm{d} S>0$, $\mathrm{d} V_{B_{2}} / \mathrm{d} B G_{2} t_{2}>0, \mathrm{~d} V_{B_{2}} / \mathrm{d} Q U_{1}>0$. In summary, it can be seen that the increase in benefits after technological improvement in the power industry, the increase in government subsidies and penalties, the increase in environmental taxes and fees that can be saved, and the increase in the cost of saving coal, or the reduction of technology research and development costs in the power industry can all promote the power industry's acceleration of technological innovation.

Proposition 4. The probability that the power industry chooses the "technological innovation" strategy is positively related to the probability that the local government chooses "strengthen environmental regulation" and the probability that coal companies choose "cleaner production." 

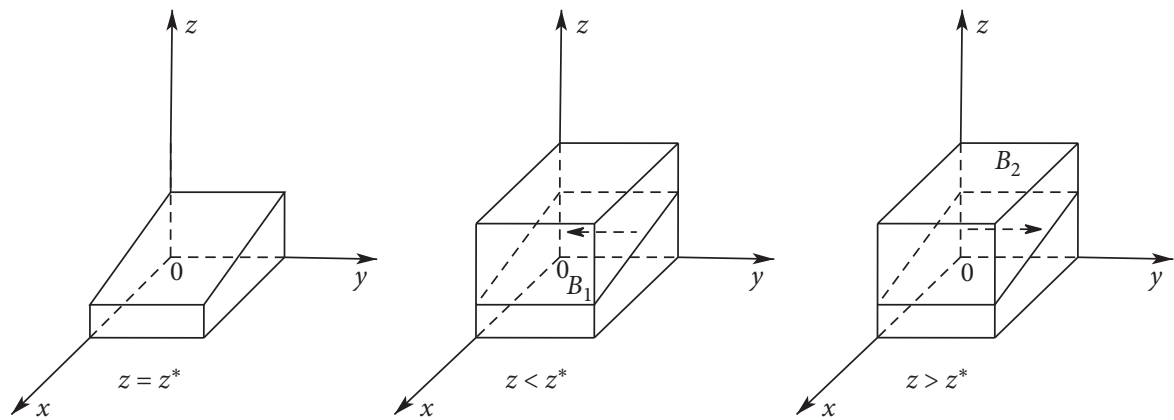

Figure 3: Phase diagram of strategy evolution of the power industry.

Proof. The proving process is the same as Proposition 2.

The probability of the power industry choosing the strategy of "technological innovation" increases with the increase of the local government choosing the strategy of "strengthening environmental regulation" and the probability of coal enterprises choosing the strategy of "cleaner production," suggesting that the local government's strengthening of environmental regulations can promote the technical innovation of the power industry, and the power industry technology innovation needs the government's strict regulation. The impact of coal companies' strategic choices on the power industry is further reflected in coal price fluctuation, and the promotion of cleaner production by coal companies can help the power industry in technological innovation.

4.3. Stability Analysis of Coal Enterprise. Assuming that the expected profit when the coal company chooses the "cleaner production" strategy is $U_{z}$, the expected profit when the coal company chooses the "remain unchanged" strategy is $U_{1-z}$, and the average expected profit is $\overline{U_{3}}$, we can obtain

$$
\left\{\begin{array}{l}
U_{z}=x y\left(I_{3}+S-Q U_{1}+B t_{3} G_{3}-C_{3}\right)+x(1-y)\left(I_{3}+S+B t_{3} G_{3}-C_{3}\right) \\
+(1-x) y\left(I_{3}-Q U_{1}+B t_{3} G_{3}-C_{3}\right)+(1-x)(1-y)\left(I_{3}+B t_{3} G_{3}-C_{3}\right) \\
U_{1-z}=x y\left(-Q U_{0}-P\right)+x(1-y)(-P)+(1-x) y\left(-Q U_{0}\right) \\
\overline{U_{3}}=z U_{z}+(1-z) U_{1-z} .
\end{array}\right.
$$

The replication dynamic equation of coal enterprise strategy selection is

$$
\begin{aligned}
F(z)= & \frac{\mathrm{d} z}{\mathrm{~d} t}=(1-z) z\left[I_{3}-C_{3}+B G_{3} t_{3}+(P+S) x\right. \\
& \left.+Q\left(U_{0}-U_{1}\right) y\right] .
\end{aligned}
$$

Taking the derivative of $F(z)$,

$$
\begin{aligned}
\frac{\mathrm{d} F(z)}{\mathrm{d} z}= & (1-2 z)\left[I_{3}-C_{3}+B G_{3} t_{3}\right. \\
& \left.+(P+S) x+Q\left(U_{0}-U_{1}\right) y\right] .
\end{aligned}
$$

Let $F(z)=0$, we can get $z=0, \quad z=1$, $x=\left[C_{3}-I_{3}-B G_{3} t_{3}+Q\left(U_{1}-U_{0}\right) y\right] /(P+S)=x^{*}$.

According to the stability theorem of differential equations, if the probability of selecting cleaner production in the coal enterprise is stable, it must meet the conditions that $F(z)=0$ and $\mathrm{d}(F(z)) / \mathrm{d} z<0$. When $x=x^{*}, F(z) \equiv 0$, any value of $z$ is the evolutionary stable strategy of coal enterprises, and the strategy of coal enterprises does not change with time. When $x \neq x^{*}$, there are two situations that result:
(1) When $C_{3}-I_{3}-B G_{3} t_{3}+Q\left(U_{1}-U_{0}\right) y>0$, we can get $x^{*}>0$. For any $x$ in the interval $[0,1]$, when $x>x^{*}$, we can get $\mathrm{d} F(z) /\left.\mathrm{d} z\right|_{z=1}<0$ and $\mathrm{d} F(z) /\left.\mathrm{d} z\right|_{z=0}>0$. Thus, $z=1$ is the steady state. When $x<x^{*}$, we can get $\mathrm{d} F(z) /\left.\mathrm{d} z\right|_{z=1}>0$ and $\mathrm{d} F(z) /\left.\mathrm{d} z\right|_{z=0}<0$. Thus, $z=0$ is the steady state.

(2) When $C_{3}-I_{3}-B G_{3} t_{3}+Q\left(U_{1}-U_{0}\right) y<0$, we can get $x^{*}<0$. Because $x \in[0,1]$, then $x>x^{*}$ is held, we can get $\mathrm{d} F(z) /\left.\mathrm{d} z\right|_{z=1}<0$ and $\mathrm{d} F(z) /\left.\mathrm{d} z\right|_{z=0}>0$. Thus, $z=1$ is the steady state. The strategy evolution diagram of the coal enterprise is shown in Figure 4.

Proposition 5. The probability that coal companies choose "cleaner production" is positively related to the increase in revenue brought about by cleaner production, government subsidies and penalties, and the environmental taxes and fees that can be saved, and is negatively related to the decrease in coal sales revenue and the cost of clean production inputs.

Proof. Figure 4 shows that the probability of coal enterprises adopting "remain unchanged" and "cleaner production" strategies are the volumes of $D_{1}$ and $D_{2}$ respectively, calculated as 

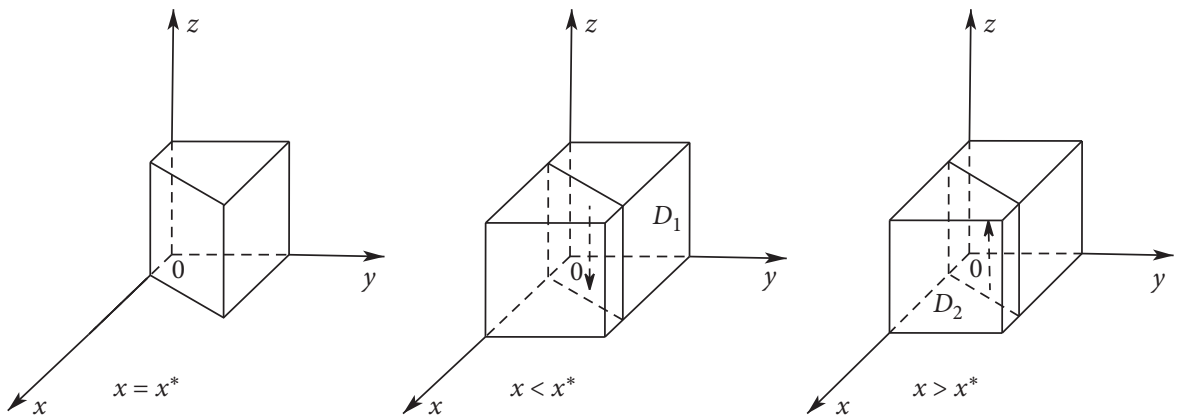

Figure 4: Phase diagram of strategy evolution of coal enterprises.

$$
\begin{aligned}
V_{D_{1}} & =\int_{0}^{1} \int_{0}^{1} \frac{\left[C_{3}-I_{3}-B G_{3} t_{3}+Q\left(U_{1}-U_{0}\right) y\right]}{(P+S)} \mathrm{d} y \mathrm{~d} z \\
& =\frac{\left[2 C_{3}-2 I_{3}-2 B G_{3} t_{3}+Q\left(U_{1}-U_{0}\right)\right]}{2(P+S)}, \\
V_{D_{2}} & =1-V_{D_{2}}=\frac{\left[-2 C_{3}+2 I_{3}+2(P+S)+2 B G_{3} t_{3}-Q\left(U_{1}-U_{0}\right)\right]}{2(P+S)} .
\end{aligned}
$$

According to the expression of $V_{D_{2}}$, when the coal enterprise adopts "cleaner production" strategy, the first-order partial derivative of each factor can be obtained: $\mathrm{d} V_{D_{2}} / \mathrm{d} C_{3}<0, \quad \mathrm{~d} V_{D_{2}} / \mathrm{d} I_{3}>0, \quad \mathrm{~d} V_{D_{2}} / \mathrm{d} P>0, \quad \mathrm{~d} V_{D_{2}} / \mathrm{d} S>0$, $\mathrm{d} V_{D_{2}} / \mathrm{d} B G_{3} t_{3}>0, \mathrm{~d} V_{D_{2}} / \mathrm{d}\left(Q\left(U_{1}-U_{0}\right)\right)<0$. In summary, it can be seen that increasing the benefits of clean production of coal enterprises, increasing government subsidies and penalties, increasing the environmental taxes and fees that can be saved, and reducing the difference in coal sales revenue of coal enterprises or reducing the cost of clean production can all promote coal enterprises' speeding up of clean production.

Proposition 6. The probability that coal companies choose "cleaner production" strategy is positively correlated with the probability that the local government chooses "strengthening environmental regulation." However, it is negatively correlated with the probability that the power industry chooses the strategy of "technical innovation."

Proof. The proving process is the same as Proposition 2.

The probability that coal companies choose a "cleaner production" strategy increases with the increase in the probability of local governments choosing "strengthening regulation" strategy, indicating that subject to the measures taken by the local government to improve environmental regulation, coal companies must seek transformation and upgrading actively. The probability that coal companies choose the "cleaner production" strategy decreases with the increase of the probability when the power industry chooses "technological innovation" strategy. This conclusion contradicts our analysis in the previous problem description because as the demand for coal in the power industry has drastically reduced after technological upgrades, the income of coal companies from coal sales has also plummeted, which is far from covering the cost of clean production; thus, companies have insufficient motivation for independent innovation and will eventually choose to maintain the status quo.

4.4. Stability Analysis of Tripartite Evolutionary Game System. It can be seen from the above that formulas (2), (6), and (10) constitute a three-dimensional continuous dynamic system:

$$
\left\{\begin{array}{l}
F(x)=(1-x) x\left[-C_{1}+2 P+F(y-1)(z-1)-(P+S)(y+z)\right], \\
F(y)=(1-y) y\left[-C_{2}+I_{2}+B G_{2} t_{2}+(P+S) x+Q\left(U_{0}(1-z)+U_{1} z\right)\right] \\
F(z)=(1-z) z\left[I_{3}-C_{3}+B G_{3} t_{3}+(P+S) x+Q\left(U_{0}-U_{1}\right) y\right]
\end{array}\right.
$$

Let $F(x)=0, F(y)=0, F(z)=0$, we can get 9 system equilibrium points: $E_{1}(0,0,0), E_{2}(0,1,0), E_{3}(0,0,1)$, $E_{4}(1,0,0), E_{5}(1,0,1), E_{6}(1,1,0), E_{7}(0,1,1), E_{8}(1,1,1)$, and $E_{8}(1,1,1)$, where $E_{9}\left(x^{*}, y^{*}, z^{*}\right)$ is the solution of formula (9).

$$
\left\{\begin{array}{l}
{\left[-C_{1}+2 P+F(y-1)(z-1)-(P+S)(y+z)\right]=0} \\
{\left[I_{2}-C_{2}+B G_{2} t_{2}+(P+S) x+Q\left(U_{0}(1-z)+U_{1} z\right)\right]=0} \\
{\left[I_{3}-C_{3}+B G_{3} t_{3}+(P+S) x+Q\left(U_{0}-U_{1}\right) y\right]=0 .}
\end{array}\right.
$$

According to Selten's research, only when $X$ is a strict Nash equilibrium, the strategy combination $X$ is gradually stable in a multi-agent evolutionary game dynamic replication system [56]. The strict Nash equilibrium is a pure strategy Nash equilibrium. Therefore, the asymptotically stable state must be evolutionary stable strategies (ESS), and it must be a pure strategy Nash equilibrium. $E_{9}\left(x^{*}, y^{*}, z^{*}\right)$ is a nonstrict Nash equilibrium and does not meet the evolutionary stability criterion of the multi-agent model [22]. Therefore, we only need to discuss the asymptotic stability of the eight pure strategy equilibrium points of $E_{1-8}$ for the 
abovementioned dynamic replication system. To simplify the calculation, let $A=P+S, \quad D=I_{2}-C_{2}+B G_{2} t_{2}$, $E=Q\left(U_{0}-U_{1}\right)$, and $H=I_{3}-C_{3}+B G_{3} t_{3}$, we can see that $A>0$ and $E<0$.

$$
J=\left[\begin{array}{c}
(2 x-1)\left(C_{1}-2 P-F(y-1)(z-1)+A(y+z)\right) \\
y(1-y) A \\
z(1-z) A
\end{array}\right.
$$

According to the first theorem of Lyapunov [57], all the eigenvalues of the Jacobian matrix corresponding to the asymptotically ESS must be less than 0 . Taking the equilibrium point $E_{1}(0,0,0)$ as an example to discuss its asymptotic stability, the characteristic value of the Jacobian matrix at $\mathrm{E}_{1}(0,0,0)$ of the dynamic replication system is: $\lambda_{1}=-C_{1}+F+2 P, \lambda_{2}=D+Q U_{0}, \lambda_{3}=H$. Since $F>C_{1}$, thus, $\lambda_{1}>0, E_{1}$ is an unstable point. Similarly, the gradual stability of the remaining 7 equilibrium points can be judged, and the results are shown in Table 3.

Scenario 1. When $D+A+Q U_{0}<0$ and $H+A<0$, that is, when the cost of innovation in the power industry is higher than the sum of the increase in revenue brought about by innovation and the savings in coal purchase costs and pollution discharge cost, and government subsidies and punishments, as well as when the clean production cost is higher than the sum of the benefits brought about by clean production, the government subsidies and punishments, and the saved pollution discharge cost, as shown in Table 3, there is only one stable point $E_{4}(1,0,0)$ in the dynamic replication system, which corresponds to the strategic set of (strengthening environmental regulation, remaining unchanged, remaining unchanged). In this case, the failure to promote the technological innovation of coal power enterprises by local government's strengthened environmental regulation is a situation that should be avoided in policymaking.

Scenario 2. When $D+A+Q U_{1}<0$ and $H+A>0$, that is, when the cost of innovation in the power industry is higher than the sum of the increase in revenue brought about by innovation and the savings in coal purchase costs and pollution discharge cost, and government subsidies and punishments, as well as when the clean production cost is lower than the sum of the benefits brought about by clean production, the government subsidies and punishments, and the saved pollution cost, as shown in Table 3, there is only one stable point $E_{5}(1,0,1)$ in the dynamic replication system, which corresponds to the strategic set of (strengthening environmental regulations, remaining unchanged, cleaner production). In this case, because power industry cannot afford the high cost of technological innovation, even though local governments choose to strengthen environmental regulations and coal companies
By using the replication dynamic equation, the Jacobian matrix of the tripartite game can be obtained as choose cleaner production, they still fail to change the power industry's strategic choices.

Scenario 3. When $D+A+Q U_{0}>0$ and $H+A+E<0$, that is, when the cost of innovation in the power industry is lower than the sum of the increase in revenue brought about by innovation and the savings in coal purchase costs and pollution discharge cost, and government subsidies and punishments, as well as when the clean production cost is higher than the sum of the benefits brought about by cleaner production, government subsidies, and punishments, the saved pollution discharge cost, and reduced coal sales revenue. It can be seen from Table 3 that there is only one stable point $E_{6}(1,1,0)$ in the dynamic replication system, which corresponds to the strategic set of (strengthening environmental regulations, technical innovation, remaining unchanged). In this case, even if local governments strengthen environmental regulations and reduce coal consumption in the downstream power industry, it is still the optimal strategy for coal companies to maintain the status quo to bring in more benefits.

Scenario 4. When $D+Q U_{1}>0$ and $H+E>0$, that is, when the cost of innovation in the power industry is lower than the sum of the increase in revenue brought about by innovation and the savings in coal purchase costs and pollution discharge cost, as well as when the clean production cost is lower than the sum of the benefits brought about by cleaner production, saved pollution discharge costs, and reduced coal sales revenue, as shown in Table 3 , there is only one stable point $E_{7}(0,1,1)$ in the dynamic replication system, which corresponds to the strategic set of (maintaining current regulations, technical innovation, cleaner production). In this case, even if the local government still maintains the current environmental regulations, when the benefits of innovation can cover the cost of innovation, coal companies and the power industry will spontaneously choose to carry out technological innovation.

Based on the research hypothesis, the equilibrium points of Scenarios $1-4$ are $E_{4}(1,0,0), E_{5}(1,0,1), E_{6}(1,1,0)$, and $E_{7}(0,1,1)$. For equilibrium point $E_{4}(1,0,0)$, local governments have adopted measures to strengthen environmental regulation, but they have still failed to change the current production status of coal-fired power companies and have no research value. For the equilibrium point $E_{7}(0,1,1)$, the 


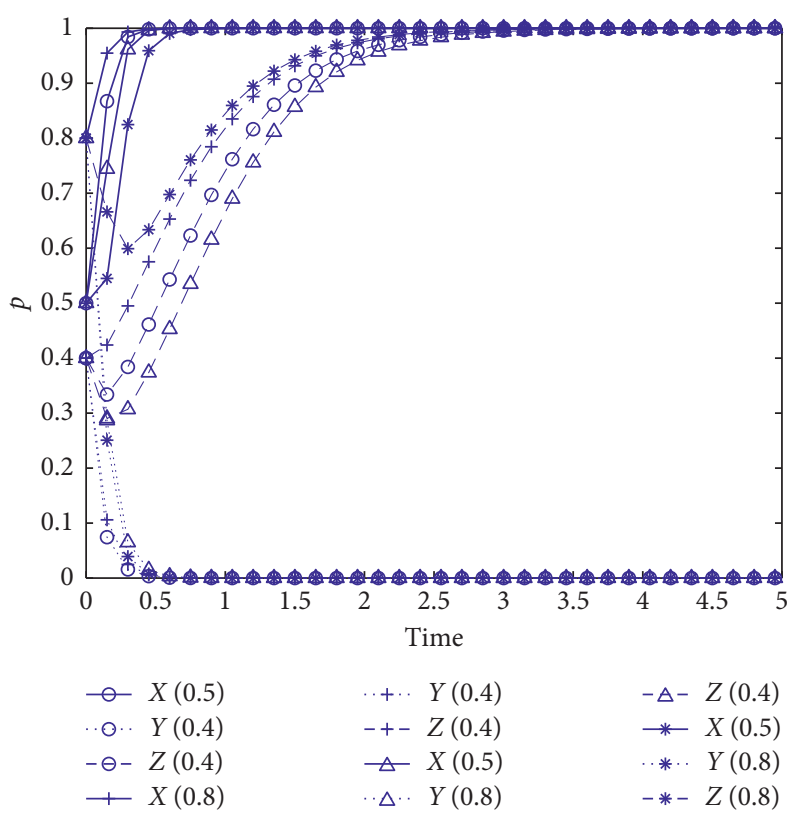

(a)

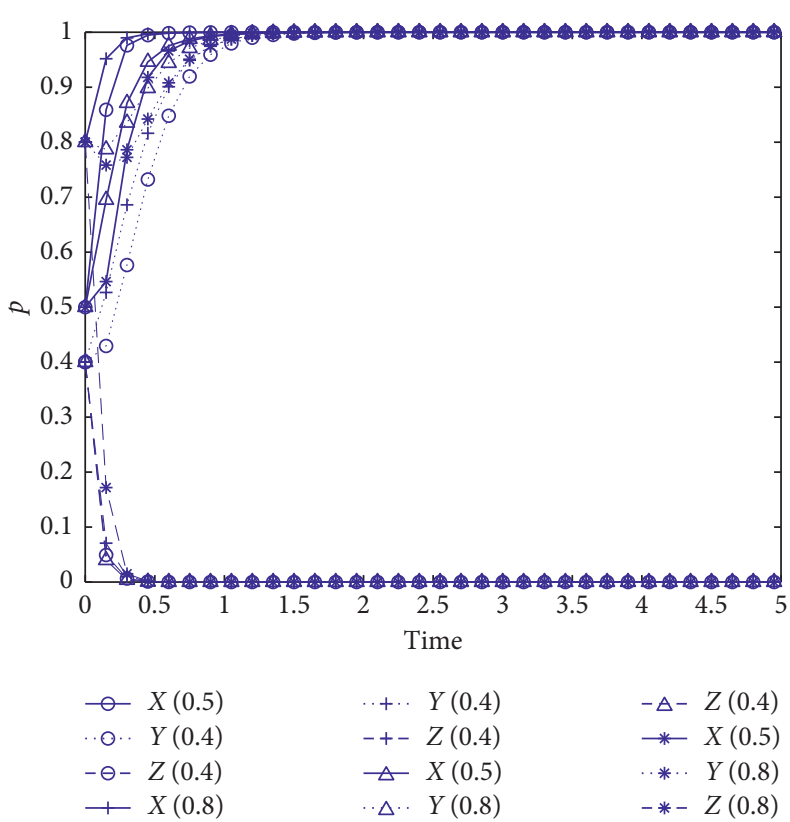

(b)

FIgURE 5: Evolution path under different initial strategies. (a) Scenario 2. (b) Scenario 3.

that local governments' strengthening of environmental regulations has a significant policy effect and reveals the indispensable role of local governments in promoting industrial upgrading.

\subsection{The Impact of Environmental Tax on the Stability of Game} Strategy. Coal and power companies are regarded as high polluting industries and are sensitive to environmental taxes. Environmental taxes of different levels have different impacts on the power industry and coal companies' strategic choices. Therefore, to analyze environmental taxes' impact on the evolutionary game process and results, based on the initial values, we keep the remaining parameters unchanged, set three groups of values: $B=14 ; B=7$; and $B=1.2$. The simulation result is shown in Figure 6.

It can be seen from Figure 6 that under Scenario 2, only when the environmental tax standard $(B)$ reaches the maximum value, the coal companies' strategic choice tends to be a stable state of cleaner production. And as $B$ drops to the minimum value within the constraints, the coal companies' strategic choices have changed from cleaner production to remaining unchanged. Similarly, under Scenario 3, the larger the $B$, the shorter the evolution time required for the power industry to reach a stable state of technological innovation. The above analysis further verifies Propositions 3 and 5. Under the lower environmental tax, the power industry has insufficient motivation to break through the original technology; a higher environmental tax can promote clean production for coal enterprises. We can conclude that the adoption of the highest environmental tax by local governments is essential to reduce the production capacity of coal companies and optimize the energy use structure of the power industry. Levying a carbon tax can reduce carbon emissions. However, due to the diverse and heavy tax burdens of the coal industry, the normal operations of coal enterprises may be affected considering reality. Besides, environmental taxes will also hinder investment in renewable energy [58]. Therefore, local governments should make reasonable adjustments to environmental taxes based on actual local conditions and seek a balance between corporate innovation and environmental protection.

5.3. The Impact of Government Subsidy and Punishment Intensity on the Stability of Game Strategy. Most local governments strengthen environmental regulations and encourage coal power companies to carry out technological innovation by issuing administrative orders and formulating supporting subsidies and punishments. To analyze the influence of government subsidies and punishments on the evolutionary game process and results, based on the initial values, we keep the remaining parameters unchanged and set four groups of simulation values: $P=10, S=3 ; P=10$, $S=0, P=0, S=3$; and $P=0, S=0$. The simulation result is shown in Figure 7.

It can be seen from Figure 7 that under Scenario 2 when the government subsidies and penalties become more and more powerful, the probability of coal companies choosing cleaner production increases significantly; under Scenario 3, increasing subsidies and penalties can speed up the evolution rate of technological innovation in the power industry. No matter under Scenarios 2 or 3, the local government only issues subsidies or only adopts punitive measures, and the impact on the power industry and coal companies' strategic choices is not as practical as the simultaneous use of 


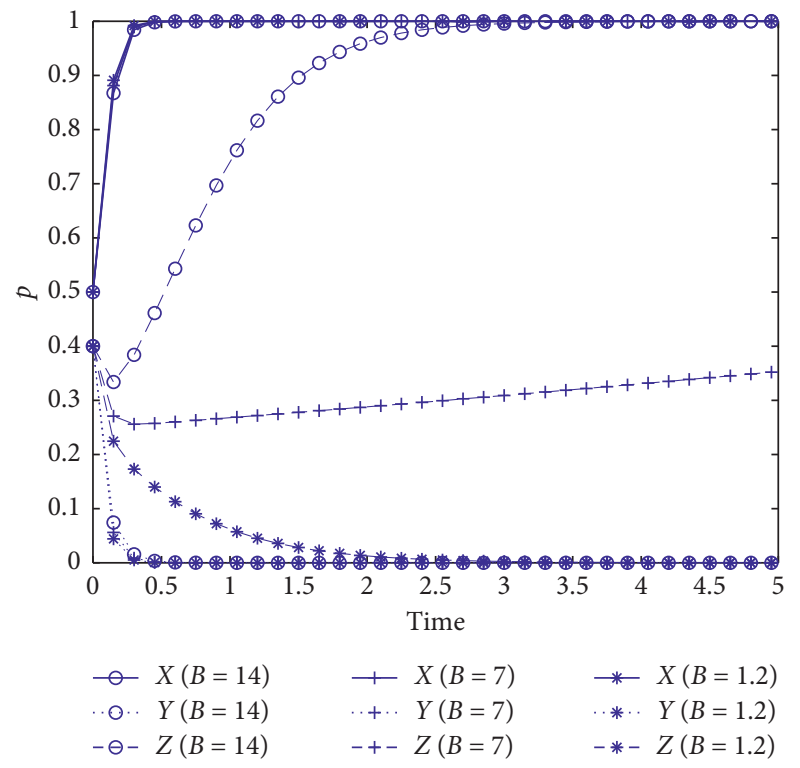

(a)

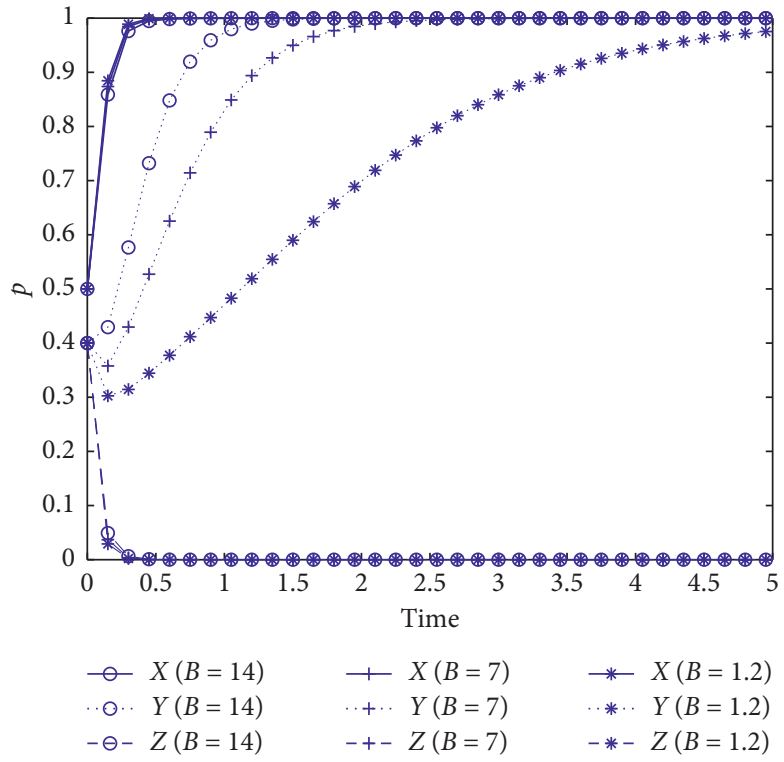

(b)

Figure 6: Evolution path under different environmental tax standards. (a) Scenario 2. (b) Scenario 3.
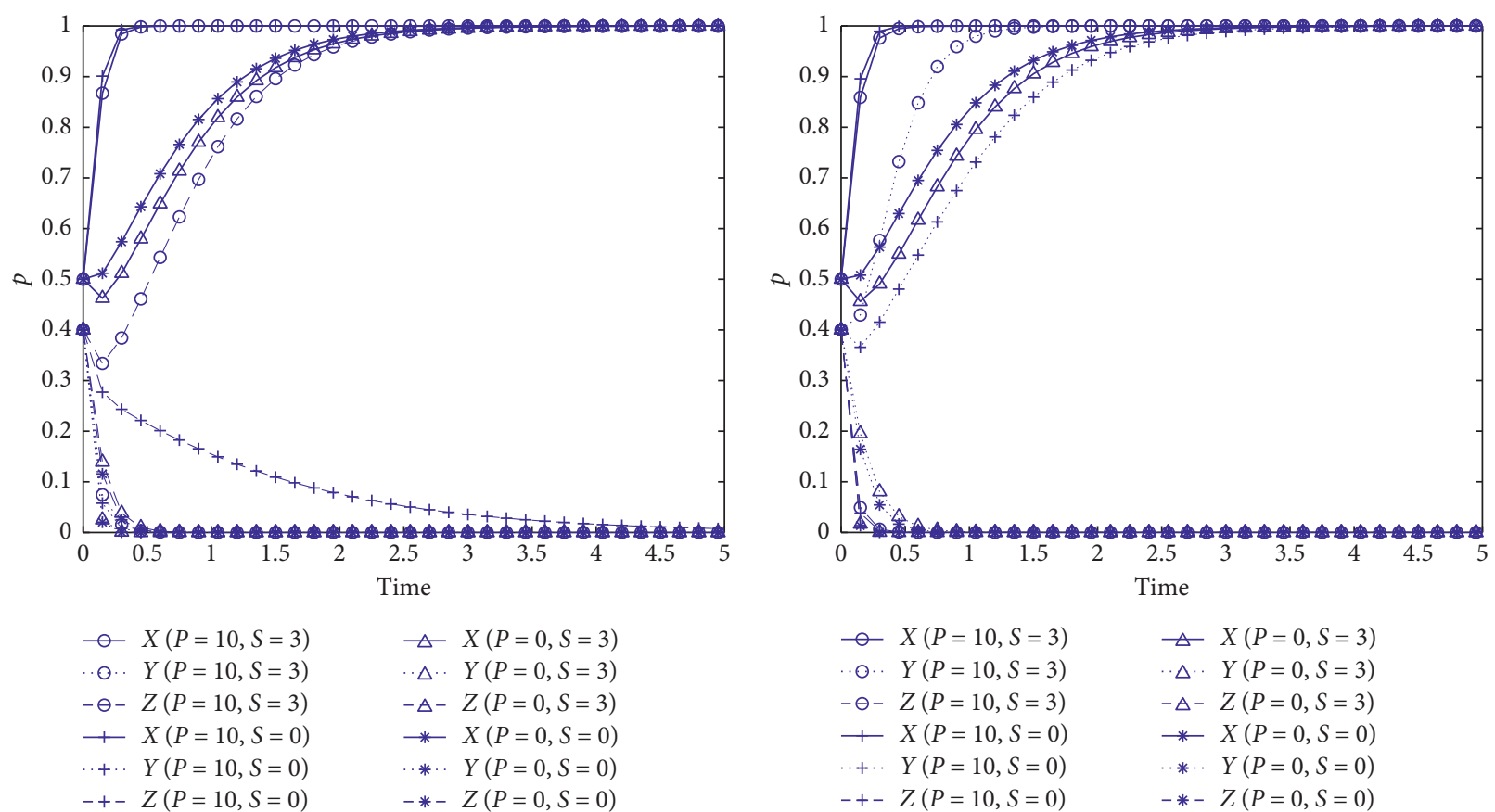

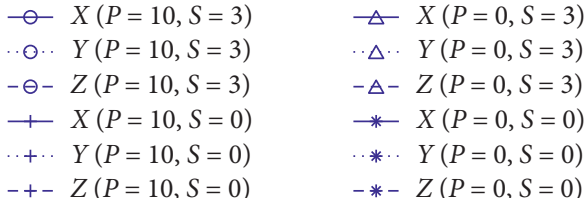

(a) (b)

Figure 7: Evolutionary paths under different levels of subsidies and penalties. (a) Scenario 2. (b) Scenario 3.

subsidies and punishments; the effect of adopting the subsidy policy only is not as good as the policy of adopting penalties only; penalizing enterprises that violate the regulations alone can significantly increase the rate of evolution of local governments. When local governments do not take any subsidies and impose penalties $(P=0, S=0)$, coal and power companies choose to keep the existing technology unchanged. Even if the local government eventually tends to strengthen the stable state of environmental regulation, due to the decline in revenue, the evolution and stability of the local government will be extended. The above analysis also further verifies Propositions 1, 3, and 5. It can be seen that the local governments adopt a two-pronged approach to increase environmental taxes, subsidies, and punishments, 


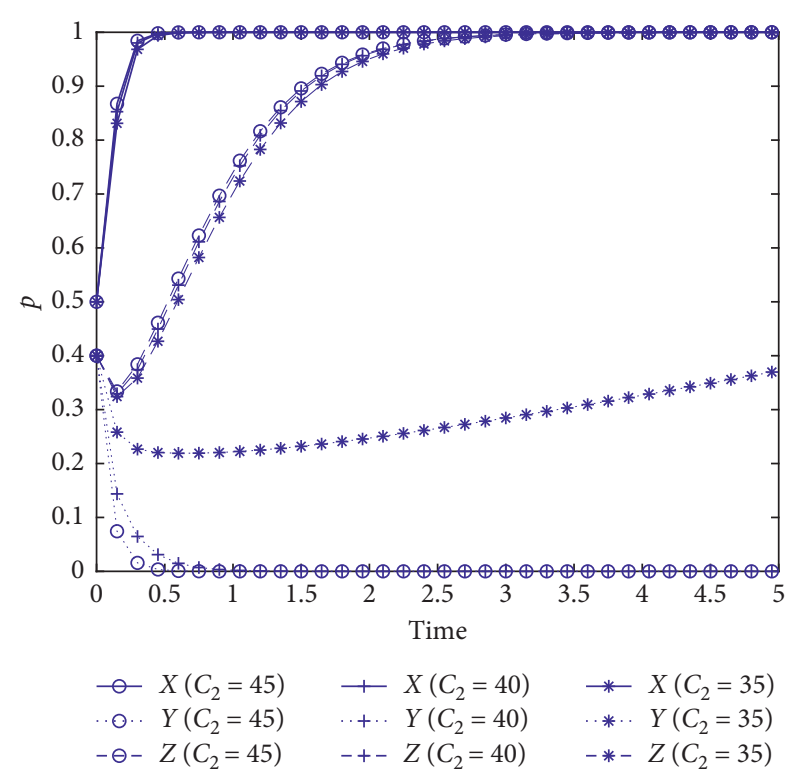

(a)

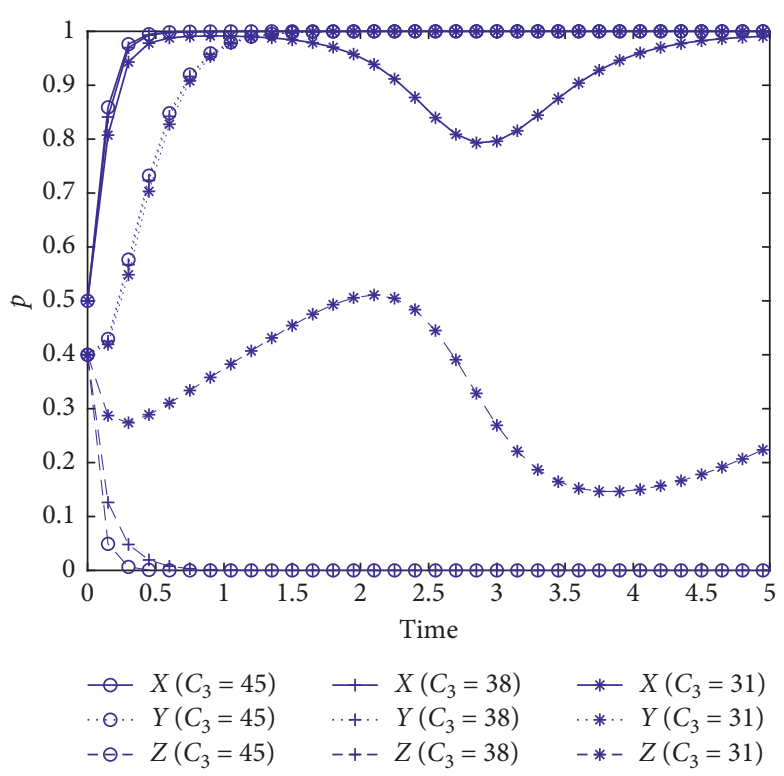

(b)

FIgURE 8: Evolutionary paths under different technological innovation costs. (a) Scenario 2. (b) Scenario 3.

and strictly supervise the coal and power industries, which will promote the transformation and upgrading of the coal power industry.

5.4. The Impact of Technological Innovation Cost on the Stability of Game Strategy. The cost of technological innovation in the coal-fired power industry is high. Except for large state-owned enterprises, most small and medium-sized enterprises cannot afford considerable costs in the short term; therefore, they lack technological innovation motivation. To analyze the impact of technological innovation costs on the evolutionary game process and results, based on the initial values, we keep the remaining parameters unchanged and set two groups of values: $C_{2}=45, C_{2}=40, C_{2}=$ $35 ; C_{3}=45, C_{3}=38, C_{3}=31$. The simulation result is shown in Figure 8.

It can be seen from Figure 8 that under Scenario 2, with the gradual decrease of $C_{2}$, the power industry's strategic choices no longer tend to be stable, but display a trend toward technological innovation strategies. Under Scenario 3 , with the decrease of $C_{3}$, the strategic choices of coal companies fluctuate sharply and are no longer stable in a passive state that remains unchanged. Moreover, when coal enterprises' innovation cost reduces to a certain level, local governments and coal enterprises' strategic choices are distributed symmetrically. The above analysis further verifies Propositions 3 and 5. It can be seen that the cost of innovation is a crucial factor affecting the transformation and upgrading of enterprises. Most companies use financing channels like loan to plan for technological upgrades. However, given that financial institutions nowadays do not know much about the operating characteristics of coal and electricity companies, existing financial products lack applicability and high financing costs. Besides, the lack of collateral for small and medium-sized coal enterprises makes it difficult to meet the financing needs for technological innovation, which further restrains enterprise innovation motivation.

5.5. The Impact of Coal Saving on the Stability of Game Strategy. With the strategic transformation of the power industry, the demand for thermal power will continue to decline. The strategic choices of coal companies are bound to change to cater to the market. The coal saving $Q$ brought about by technological innovation in the power industry is used to describe coal companies' sensitivity to the power industry strategy. Based on the initial values, we keep the remaining parameters unchanged and set three groups of values: $Q=1 ; Q=2.5 ; Q=4.5$. The simulation result is shown in Figure 9.

It can be seen from Figure 9 that under Scenario 2, with the increase of $Q$, the evolution rate of coal enterprises' choice of cleaner production slows down. In the short term, the decline in coal enterprises' operating income is an essential factor affecting cleaner production. Technology upgrades have saved coal consumption for the power industry. As the demand for coal has fallen sharply, the power industry's choice of maintaining the same strategy has slowed down and even reversed. While under Scenario 3, the impact of coal sales volume on coal enterprises' evolution is not significant for the reason that coal enterprises are more likely unable to bear the innovation costs of cleaner production actively. The above analysis further verifies Propositions 3 and 5, which shows that coal companies are susceptible to technological upgrades in the power industry. The reduction in coal market demand will further aggravate coal overcapacity. Coal companies follow market demand as an inevitable choice for sustainable development. 


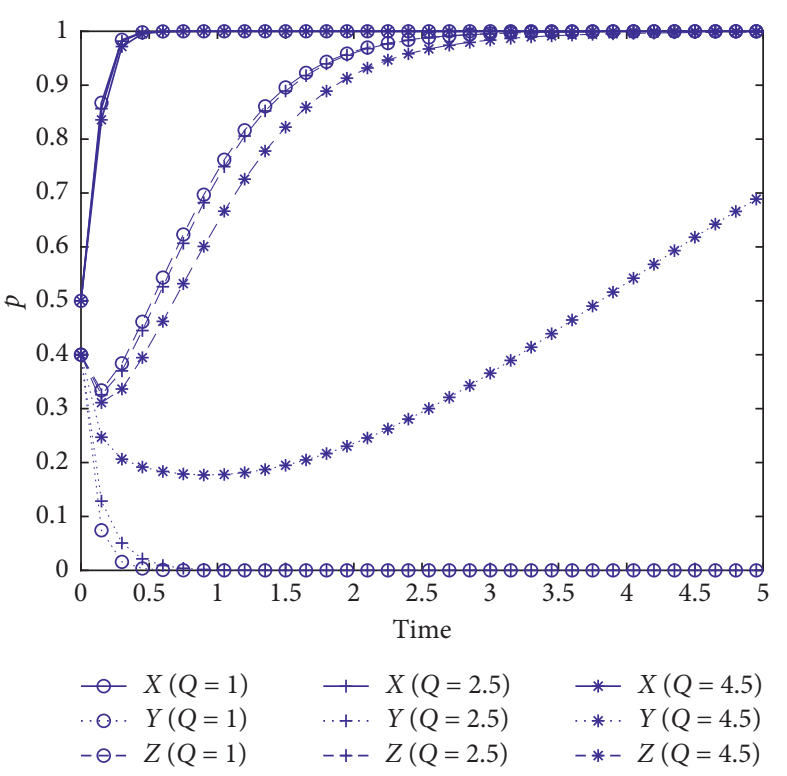

(a)

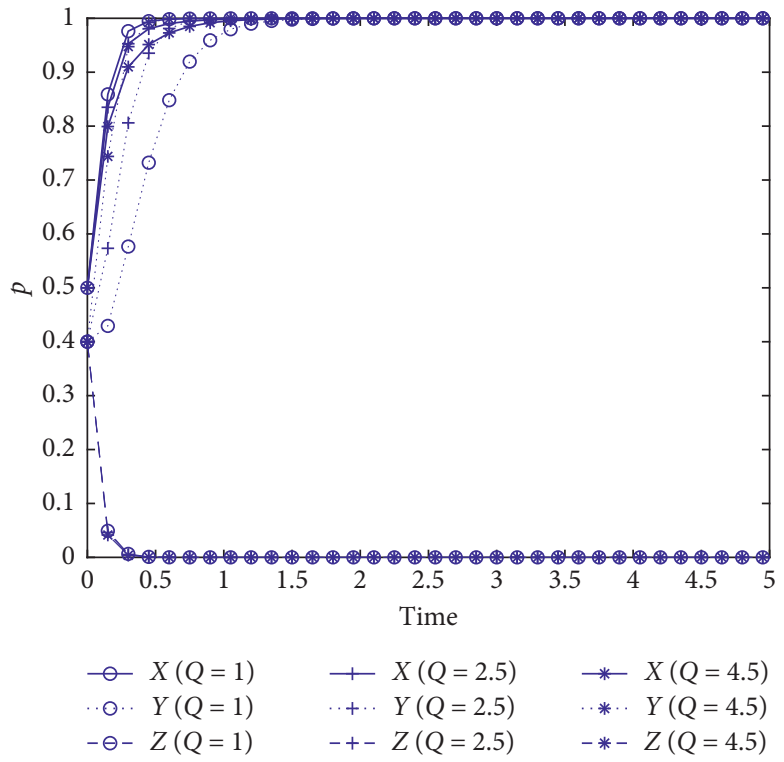

(b)

FIgURE 9: Evolution paths at different coal saving rates. (a) Scenario 2. (b) Scenario 3.

\section{Conclusions}

Based on the evolutionary game theory, this paper analyzes the evolutionary game process between local government, power industry, and coal enterprises through modeling. We analyze both the stability of a single player and the overall system, and conduct numerical simulations by adjusting factors such as the initial strategy choice of the game player, environmental taxes, government subsidies and punishments, technological innovation costs, and coal demand to explore the specific evolution path of a coal company's overcapacity under market-incentive environmental regulations. The numerical simulation analysis in this study further verifies the inferences of the stability analysis, summarizes the results of several simulations, and draws specific conclusions as follows:

(1) The actions of local governments, concurrently increasing subsidies and punishments or increasing environmental taxes, can enable coal and power companies to reach an evolutionarily stable state faster, and the simultaneous implementation of both will help to further shorten the evolution time. Increasing government subsidies to energy companies can alleviate overcapacity to a certain extent (different from $[59,60])$, but it is not as effective as taking punishment measures. If coal-fired power companies actively choose technological innovation, local governments will not change the current regulatory policies. Under this condition, the benefits of companies after innovation are far greater than the costs. In reality, this situation is difficult to exist in the early stages of technological innovation. It also shows that increasing environmental regulation is an inevitable choice for local governments to help enterprises transform and upgrade and resolve overcapacity.
(2) The cost of enterprise technological innovation is a key factor affecting the stability of evolution. When the cost of innovation is lower, enterprises tend to choose technological innovation. Therefore, in technological innovation and capacity reduction of coal power enterprises, financial support should be increased. The government provides many subsidies to thermal power plants every year. Although subsidies may lead to inefficient use of resources [61], appropriate subsidies are necessary to transform the coal and power industries.

(3) From the perspective of initial strategic choices, the strategic choices of local governments have a profound impact on the evolution and stability of coalfired power companies. Reducing the cost of implementing environmental regulations and increasing the penalties for overcapacity can shorten the evolution time for local governments to strengthen environmental regulations, which will help realize the coordinated development of the three parties ultimately. Technological innovation in the power industry will reduce the operating income of coal companies and delay the evolutionary stability time for them to choose cleaner production. The increase in revenue and the reduction in both parties' costs are an essential prerequisite for coal companies and power industry's collaborative innovation.

(4) The amount of coal saved after technological innovation is the focus of attracting power industry adjustment strategies. A certain level of coal saving will promote the power industry to carry out technological innovation actively. It also shows that with the continuous upgrading of power generation technology in the power industry, renewable energy 
and clean energy will continue to swallow the coal market. The importance of clean coal production has become more prominent.

According to the above research conclusions, the following policy implications can be drawn:

(1) When local governments implement specific environmental regulations and policies, there are often certain deviations related to their interests, which may result in the phenomenon that the coal industry can hardly reach the goal of reducing the production capacity. The central government must strengthen the supervision on local governments, and local governments must use their information advantages to rationally and timely regulate local environmental regulations. Overcapacity reduction is a task that every department should pay attention to. Taking a series of measures to reduce the cost of government environmental regulations can effectively promote local governments to strengthen their attention to overcapacity reduction tasks. On the other hand, the follow-up work to reduce overcapacity also requires the government to take supporting measures to speed up the process of transformation and upgrading of coal power enterprises by adhering to the principle of combining market forces with government support.

(2) Economic development cannot be completely separated from the support of the coal industry; in other words, coal companies must assess the situation and improve their competitiveness through active clean production to meet the needs of the power industry and other consumers, accelerate the withdrawal of outdated production capacity, and improve de-capacity mechanism by arranging properly the resettlement of assets, debts, and employees. The business of coal and power companies involves vast investment, and their technological innovation costs and difficulties are also high. Coal mining companies should actively enhance their research to promote clean production technologies such as unharmed coal and intelligent mining to reduce subsequent operating costs and cater to green and era requirements of low-carbon development. In addition, given that many small and medium-sized coal companies do not have the economic strength to increase investment in clean production, planning mergers and acquisitions with other high-quality coal companies may be a good choice for their future development.

(3) The existing differentiated industrial lending policies in the coal industry have given great support to highquality companies, forcing "zombie companies” to withdraw from the market voluntarily. However, this has also made it more difficult for some small and medium-sized coal companies with good credit to obtain financing, thus making it difficult for them to put clean production into action. Therefore, it is necessary to optimize the existing big data platforms such as the China (Taiyuan) Coal Trading Center and improve the credit ratings for coal companies. Financial institutions should meet the financial needs of high-quality coal companies and innovate inclusive financial products so as to achieve the goal of "structural reduction of production capacity and optimization of production capacity."

This study has certain limitations: Firstly, local governments, power industry, and coal companies are in a complex system that many factors affect their strategic choices, and this study is not comprehensive enough to consider the influencing factors in the tripartite game process. Secondly, due to the limitations of data acquisition and the ideality of parameter assignment, we only carried out numerical simulations at the industry level. In the next step, we will conduct more profound research in combination with actual cases.

\section{Data Availability}

The data used to support the findings of this study in Section 5 "Simulation Analysis" are included within the paper.

\section{Conflicts of Interest}

The authors declare that they have no conflicts of interest.

\section{Acknowledgments}

This study was supported by Major Scientific and Technological Innovation Projects in Shandong Province (Project no. 2018CXGC0703).

\section{References}

[1] B. Atems and C. Hotaling, "The effect of renewable and nonrenewable electricity generation on economic growth," Energy Policy, vol. 112, pp. 111-118, 2018.

[2] W. Li, P. L. Younger, Y. Cheng et al., "Addressing the $\mathrm{CO}_{2}$ emissions of the world's largest coal producer and consumer: lessons from the Haishiwan Coalfield, China," Energy, vol. 80, pp. 400-413, 2015.

[3] M. Blondeel and T. Van de Graaf, "Toward a global coal mining moratorium? A comparative analysis of coal mining policies in the USA, China, India and Australia," Climatic Change, vol. 150, no. 1-2, pp. 89-101, 2018.

[4] J. Stich, S. Ramachandran, T. Hamacher, and U. Stimming, "Techno-economic estimation of the power generation potential from biomass residues in Southeast Asia," Energy, vol. 135, pp. 930-942, 2017.

[5] C. Zhu, R. Fan, and J. Lin, "The impact of renewable portfolio standard on retail electricity market: a system dynamics model of tripartite evolutionary game," Energy Policy, vol. 136, 2020.

[6] A. Aslani and K.-F. V. Wong, "Analysis of renewable energy development to power generation in the United States," Renewable Energy, vol. 63, pp. 153-161, 2014.

[7] J. P. C. Bento, N. Szczygiel, and V. Moutinho, "Fossil fuel power generation and economic growth in Poland," Energy 
Sources, Part B: Economics, Planning, and Policy, vol. 12, no. 10, pp. 930-935, 2017.

[8] R. Zaman, C. Hofer, and T. Brudermann, "One step ahead, two steps backwards: energy transitions and coal in developing countries," in Proceedings of the 2018 International Conference and Utility Exhibition on Green Energy for Sustainable Development (ICUE), Phuket, Thailand, October 2018.

[9] A. Gupta and D. Spears, "Health externalities of India's expansion of coal plants: evidence from a national panel of 40,000 households," Journal of Environmental Economics and Management, vol. 86, pp. 262-276, 2017.

[10] S. Moret, F. Babonneau, M. Bierlaire, and F. Maréchal, "Overcapacity in European power systems: analysis and robust optimization approach,” Applied Energy, vol. 259, 2020.

[11] Y. Feng, S. Wang, Y. Sha, Q. Ding, J. Yuan, and X. Guo, "Coal power overcapacity in China: province-level estimates and policy implications," Resources, Conservation and Recycling, vol. 137, pp. 89-100, 2018.

[12] F. Wang, L. Feng, J. Li, and L. Wang, "Environmental regulation, tenure length of officials, and green innovation of enterprises," International Journal of Environmental Research and Public Health, vol. 17, no. 7, 2020.

[13] W. Du, F. Wang, and M. Li, "Effects of environmental regulation on capacity utilization: evidence from energy enterprises in China," Ecological Indicators, vol. 113, 2020.

[14] V. Koziuk, Y. Hayda, O. Dluhopolskyi, and Y. Klapkiv, "Stringency of environmental regulations vs. global competitiveness: empirical analysis," Economics \& Sociology, vol. 12, no. 4, pp. 278-298, 2019.

[15] W. Du and M. Li, "Can environmental regulation promote the governance of excess capacity in China's energy sector? The market exit of zombie enterprises," Journal of Cleaner Production, vol. 207, pp. 306-316, 2019.

[16] J. Yuan, P. Li, Y. Wang et al., "Coal power overcapacity and investment bubble in China during 2015-2020," Energy Policy, vol. 97, pp. 136-144, 2016.

[17] E. Hille, W. Althammer, and H. Diederich, "Environmental regulation and innovation in renewable energy technologies: does the policy instrument matter?" Technological Forecasting and Social Change, vol. 153, 2020.

[18] W. van der Gaast, K. Begg, and A. Flamos, "Promoting sustainable energy technology transfers to developing countries through the CDM," Applied Energy, vol. 86, no. 2, pp. 230-236, 2009.

[19] K. Kavouridis and N. Koukouzas, "Coal and sustainable energy supply challenges and barriers," Energy Policy, vol. 36, no. 2, pp. 693-703, 2008.

[20] Y. Ma, Z. Zhang, J. Jang, and J. Qu, "Overcapacity investment and supervision fluctuation: an evolutionary game approach," Applied Economics Letters, vol. 27, no. 3, pp. 221-227, 2019.

[21] K. Jiang, D. You, R. Merrill, and Z. Li, "Implementation of a multi-agent environmental regulation strategy under Chinese fiscal decentralization: an evolutionary game theoretical approach," Journal of Cleaner Production, vol. 214, pp. 902-915, 2019.

[22] J. Sheng, W. Zhou, and B. Zhu, "The coordination of stakeholder interests in environmental regulation: lessons from China's environmental regulation policies from the perspective of the evolutionary game theory," Journal of Cleaner Production, vol. 249, 2020.

[23] F. Pan, B. Xi, and L. Wang, "Environmental regulation strategy analysis of local government based on evolutionary game theory," in Proceedings of the 2014 International
Conference on Management Science \& Engineering 21th Annual Conference Proceedings, pp. 1957-1964, Helsinki, Finland, August 2014.

[24] Y. Zhang, M. Zhang, Y. Liu, and R. Nie, "Enterprise investment, local government intervention and coal overcapacity: the case of China," Energy Policy, vol. 101, pp. 162-169, 2017.

[25] A. B. Jaffe and R. N. Stavins, "Dynamic incentives of environmental regulations: the effects of alternative policy instruments on technology diffusion," Journal of Environmental Economics and Management, vol. 29, no. 3, pp. S43-S63, 1995.

[26] B. Shi, C. Feng, M. Qiu, and A. Ekeland, "Innovation suppression and migration effect: the unintentional consequences of environmental regulation," China Economic Review, vol. 49, pp. 1-23, 2018.

[27] B. Yuan and Q. Xiang, "Environmental regulation, industrial innovation and green development of Chinese manufacturing: based on an extended CDM model," Journal of Cleaner Production, vol. 176, pp. 895-908, 2018.

[28] S. Shao, Z. Hu, J. Cao, L. Yang, and D. Guan, "Environmental regulation and enterprise innovation: a review," Business Strategy and the Environment, vol. 29, no. 3, pp. 1465-1478, 2020.

[29] M. E. Porter and C. V. D. Linde, "Toward a new conception of the environment-competitiveness relationship," Journal of Economic Perspectives, vol. 9, no. 4, pp. 97-118, 1995.

[30] M. Yi, X. Fang, L. Wen, F. Guang, and Y. Zhang, “The heterogeneous effects of different environmental policy instruments on green technology innovation," International Journal of Environmental Research and Public Health, vol. 16, no. 23, 2019.

[31] M. Gong, Z. You, L. Wang, and J. Cheng, "Environmental regulation, trade comparative advantage, and the manufacturing industry's green transformation and upgrading," International Journal of Environmental Research and Public Health, vol. 17, no. 8, 2020.

[32] B. Yu and C. Shen, "Environmental regulation and industrial capacity utilization: an empirical study of China," Journal of Cleaner Production, vol. 246, 2020.

[33] W. Li, H. Sun, D. K. Tran, and F. Taghizadeh-Hesary, "The impact of environmental regulation on technological innovation of resource-based industries," Sustainability, vol. 12, no. 17, 2020.

[34] S. Ren, X. Li, B. Yuan, D. Li, and X. Chen, "The effects of three types of environmental regulation on eco-efficiency: a crossregion analysis in China," Journal of Cleaner Production, vol. 173, pp. 245-255, 2018.

[35] Z. Chen, X. Zhang, and G. Ni, "Decomposing capacity utilization under carbon dioxide emissions reduction constraints in data envelopment analysis: an application to Chinese regions," Energy Policy, vol. 139, 2020.

[36] X. Pan, B. Ai, C. Li, X. Pan, and Y. Yan, "Dynamic relationship among environmental regulation, technological innovation and energy efficiency based on large scale provincial panel data in China," Technological Forecasting and Social Change, vol. 144, pp. 428-435, 2019.

[37] X. Li and X. Yao, "Can energy supply-side and demand-side policies for energy saving and emission reduction be synergistic? A simulated study on China's coal capacity cut and carbon tax," Energy Policy, vol. 138, 2020.

[38] S. K. Lee and S. Jang, "Re-examining the overcapacity of the US lodging industry," International Journal of Hospitality Management, vol. 31, no. 4, pp. 1050-1058, 2012. 
[39] Y. Ju and X. Wang, "Understanding the capacity utilization rate and overcapacity of China's coal industry and interprovincial heterogeneity," IEEE Access, vol. 7, pp. 111375111386, 2019.

[40] X. Shi, B. Rioux, and P. Galkin, "Unintended consequences of China's coal capacity cut policy," Energy Policy, vol. 113, pp. 478-486, 2018.

[41] J. Dzonzi-Undi and S. Li, "SWOT analysis of safety and environmental regulation for China and USA: its effect and influence on sustainable development of the coal industry," Environmental Earth Sciences, vol. 74, no. 8, pp. 6395-6406, 2015.

[42] M. Zhang, T. Lv, Y. Zhao, and J. Pan, "Effectiveness of clean development policies on coal-fired power generation: an empirical study in China," Environmental Science and Pollution Research, vol. 27, no. 13, pp. 14654-14667, 2020.

[43] Y. Zhang, J. Orbie, and S. Delputte, "China's climate change policy: central-local governmental interaction," Environmental Policy and Governance, vol. 30, no. 3, pp. 128-140, 2020.

[44] M. Liu, M. Chen, and G. He, "The origin and prospect of billion-ton coal production capacity in China," Resources, Conservation and Recycling, vol. 125, pp. 70-85, 2017.

[45] X. Yao, X. Zhang, and Z. Guo, "The tug of war between local government and enterprises in reducing China's carbon dioxide emissions intensity," Science of the Total Environment, vol. 710, Article ID 136140, 2020.

[46] C. Dong, Y. Qi, and G. Nemet, "A government approach to address coal overcapacity in China," Journal of Cleaner Production, vol. 278, 2021.

[47] P. del Río González, "The empirical analysis of the determinants for environmental technological change: a research agenda," Ecological Economics, vol. 68, no. 3, pp. 861-878, 2009.

[48] G.-B. Bi, W. Song, P. Zhou, and L. Liang, "Does environmental regulation affect energy efficiency in China's thermal power generation? Empirical evidence from a slacks-based DEA model," Energy Policy, vol. 66, pp. 537-546, 2014.

[49] H. Wang and T. Nakata, "Analysis of the market penetration of clean coal technologies and its impacts in China's electricity sector," Energy Policy, vol. 37, no. 1, pp. 338-351, 2009.

[50] A. P. Chikkatur, A. D. Sagar, and T. L. Sankar, "Sustainable development of the Indian coal sector," Energy, vol. 34, no. 8, pp. 942-953, 2009.

[51] R. Ramanathan, Q. He, A. Black, A. Ghobadian, and D. Gallear, "Environmental regulations, innovation and firm performance: a revisit of the Porter hypothesis," Journal of Cleaner Production, vol. 155, pp. 79-92, 2017.

[52] L. Gan, G. S. Eskeland, and H. H. Kolshus, "Green electricity market development: lessons from Europe and the US," Energy Policy, vol. 35, no. 1, pp. 144-155, 2007.

[53] X. Qian, D. Wang, J. Wang, and S. Chen, "Resource curse, environmental regulation and transformation of coal-mining cities in China," Resources Policy, 2019.

[54] Y. Li, P. Yang, and H. Wang, "Collecting coal-fired power environmental tax to promote wind power development and environmental improvement," Acta Scientifica Malaysia, vol. 2, no. 1, pp. 5-8, 2018.

[55] L. Pingkuo, P. Huan, and W. Zhiwei, "Orderly-synergistic development of power generation industry: a China's case study based on evolutionary game model," Energy, vol. 211, 2020.
[56] R. Selten, "A note on evolutionarily stable strategies in asymmetric animal conflicts," Journal of Theoretical Biology, vol. 84, no. 1, pp. 93-101, 1980.

[57] A. M. Liapunov, Stability of Motion, Academic Press, New York, NY, USA, 1966.

[58] H. Sánchez-Beltrán, C. D. M. Rodríguez, J. C. B. Triviño, P. L. Iglesias-Rey, J. S. Valderrama, and F. J. Martínez-Solano, "Characterization of modular deposits for urban drainage networks using CFD techniques," Procedia Engineering, vol. 186, pp. 84-92, 2017.

[59] H. Zhang, Y. Zheng, U. A. Ozturk, and S. Li, "The impact of subsidies on overcapacity: a comparison of wind and solar energy companies in China," Energy, vol. 94, pp. 821-827, 2016.

[60] Z. Zhu and H. Liao, "Do subsidies improve the financial performance of renewable energy companies? Evidence from China," Natural Hazards, vol. 95, no. 1-2, pp. 241-256, 2018.

[61] A. Karaev, V. Ponkratov, A. Masterov, E. Kireeva, and M. Volkova, "Cross-country analysis of the comparative efficiency of government support for coal and lignite production," International Journal of Energy Economics and Policy, vol. 10, no. 5, pp. 220-227, 2020. 